\title{
Model of Sharing Information in Supply Chain Network based on Metcalfe's Law
}

\author{
Xin Xiong ${ }^{1}$, Mingjing Guo ${ }^{* 1,2}$, Tiantian Yang ${ }^{3}$
}

1. School of Electrical Engineering, Navy University of Engineering, Wuhan, China

2. School of Science, East China University of Technology, Nanchang, China

3. Economics and Management School, Wuhan University, Wuhan, China 26569629@qq.com,gmj117@163.com*,799749353@qq.com

Keywords: Supply chain network; Metcalfe's Law; utility value; sharing information

\begin{abstract}
Aimed at the problem in measuring the utility value of supply chain network in information sharing, this paper proposed a utility value model of supply chain network based on different information sharing strategies. Through the analysis of the research status of sharing information in supply chain at present stage, this paper discusses the feasibility of applying Metcalfe's law to measure the utility value of network which was generated by information sharing in the supply chain network. In a supply chain network composed of retailers and multiple vendors as the research object, it also explained respectively the method for measuring the utility value of supply chain network when the sharing arise between "supplier-retailer" and "supplier-supplier-retailer" and calculated the utility value of network under the different information sharing strategies of the supply chain network with the number of suppliers within 30. This model further validated that the utility value of supply chain network is directly proportional to the number of enterprises nodes in a network and the full information sharing of supply chain network is the most desirable strategy to improve the efficiency of supply chain network.
\end{abstract}

\section{Introduction}

As "post-industrial era" was put forward in 1957, information and knowledge has become the determinants of enterprise competition which gradually replace the traditional material. The opening of the third industrial revolution, the integration of the Internet and Internet of things, and proposing a concept of cyber-physical system, the data and information in the enterprise was in a surge of explosive, even become a "big data". In the face of so much data of wealth, an enterprise can't just busy in storing and managing, but should be with a new prospective in using these resources to convert immaterialized and virtualized data into energy and resources for making enterprises to obtain the competitive advantages so as to improve productivity and obtain new profits.

If computers made the materials competition turning into information technology, the Internet turned the competition between enterprises into the competition between supply chains, then under the background of "big data", competition between enterprises will intensify the competition among supply chains at the present stage [1]. How to use and share the information coming from the supply chain, maximize the information utility, integrate the supply chain as an organic whole so to coordinate the operation and get the objective profits for each node enterprise, it has become a urgent question of reality.

\section{Theoretical Basis}

Since 1980s, the concept of supply chain focused on the management of the supply chain in a single enterprise. After 1990s, the supply chain network which is made up of suppliers, retails and customers began to come forward [2-3]. To coordinate the node enterprises, sharing information is more important. A harmonized supply chain network must establish on the high degree of cooperation and 
sharing information which is useful for arrangement of manufactory and distribution tasks [4]. The demand and supply information could contribute to cut inventory and enhance the operation efficiency among all the enterprises in the network. The circulation of information should strengthen trust and collaboration among all the node enterprises to the benefit of forming more closer strategic alliances in order to timely cope with the changing market demands.

About the research on sharing information in supply chains, there are three main aspects. The first aspect is the necessity and importance of sharing information in supply chain management, mainly based on the theory of the bullwhip effect on the value of sharing information in supply chain model. The mainly concept is that through sharing information, the inventory cost of upstream suppliers can be reduced by cut down the cost for maintaining safe stock and shortage cost [5-6]. The second aspect is research on motivation system in sharing information among supply chains. It is mainly based on the "principal-agent" theory, which was aimed to design the appropriate incentive mechanism to maintain and improve the information sharing in the supply chain. From the findings such as full information sharing mechanism, multi-task principal-agent model it is clear that the retails as a core enterprise in a chain should positively share information with cooperative partners and intensify willingness to share information sequentially maximize profits of the whole system [7-8]. The third aspect is research about the implementation patterns of sharing information. Based on physical networks of the Internet, intranet and extranet, the supply chain network can be combined with electronic data interchange system to set up a security and efficient communication platform for all the nodes, patterns and customers.

In conclusion, the research on supply chain and supply chain network is a process from theoretical concept, model construction to technical implementation which conforms to man's general knowledge of the natural world. However, with the advent of the fourth industrial revolution, along with emergence of new concepts such as "big data", "cloud computing", "Internet plus", the concept of supply chain management, especially in retails is facing many new challenges and problems. How to realize the information sharing in supply chain under the new situation, how to define the overall utility value of supply chain network, all of these will be highly research significance issues.

\section{The Digital Signature Based on Digital Certificate}

Nowadays, the world, called internet economy, is represented by information technology such as the Internet. Information and knowledge become the main driving power for the development of the society. In the background of information era, all the business activities must be followed with a series of competition rules, such as Metcalfe's law, Moore's law and Davudo's law. The supply chain network is network system made up of suppliers, wholesalers, retails and consumers. Based on the platform of internet, the supply chain network should be a non-closed network not a micro community. Therefore, it is possible to use Metcalfe's rule to measure the utility value of information sharing across the supply chain network.

Metcalfe's Law was named after Robert Metcalfe who was the founder of 3Com and the Ethernet's inventor. This law proposed that network costs decrease with increasing network capacity while network value increases exponentially. In other words, If there were $n$ participant nodes in a network, the value of the network can be calculated using this formula $k n(n-1)$ where $k$ was the proportionality coefficient. The explanation was as follows: Assuming that only one user installed the phone at first, the utility of the network was 0 for him because he couldn't communicate with others by phone. When the second user installed the phone, they could communicate with each other by phones and the total utility was 2 , and the marginal utility is 2 . When the third user joined in the telephone network, the total utility increased to 6 , and the marginal utility is 4 , and so on. When the number of users $n$ is large enough, the total utility of the phone users tended to be $n^{2}$. Therefore, the utility of the 
network grow with the square of the number of users [9]. Assumed that there is $V$ as the total utility value of the network, and $n$ as the number of users in the network, it showed as:

$$
V=n^{2}
$$

\subsection{Assumption.}

Based on the theory of law, this paper assumed that if the centric enterprise of the supply chain network to participate with its upstream suppliers in decision-making under the situation of completely sharing information needed, the maximum total utility value can be produced. On the one hand suppliers should adjust the purchasing and production plans reasonably to provide downstream firms with the right supply of goods just in the right time by information sharing, on the other hand retails could draw up appropriate marketing strategies through getting the information about supply of goods from their upstream nodes. So under the condition of entirely sharing information needed all the nodes enterprises in the supply chain network could increase profits and reduce the cost coping with uncertain factors so that the total utility value of the network will be improved.

\subsection{Mode Construction.}

With the increase of the nodes in the supply chain network, the overall utility is rising. Aimed to measure the value differences under different information sharing condition especially in whole and in part, this paper constructed models for calculating the total utility value of supply chain network based on Metcalfe's law.

Assumed that there is $V$ as the total utility value of the network, and $n$ as the number of nodes in the network which must be an integer than or equal to zero. As shown in Fig.1 and Fig.2, there are supplier nodes known as $S_{i}(i=1,2,3 \cdots n)$ and one retailer known as $R$. According to Metcalfe's law, the network value is proportional to the number of nodes in a network. So the formula for calculating the value to all nodes in the network is constructed as follows:

$$
V=n(n-1)
$$

For a supply chain network, there is a sub-network making up of all suppliers. To calculate the utility value of the sub-network the method of sharing information should be a key influence factor. The model for different sharing information strategies within a supply chain network are as follows:

1) Supplier-to-Retailer Model: In the Fig.1, all the suppliers only shared their inventory and production information with the retailer and the retailer also transferred its own information such as marketing demand and sale records to the upstream suppliers, then the network utility value was decided by the number of suppliers sharing information with the retailer. Adding with the two-way of information sharing, the formula is set as:

$$
V_{1}=2 n
$$

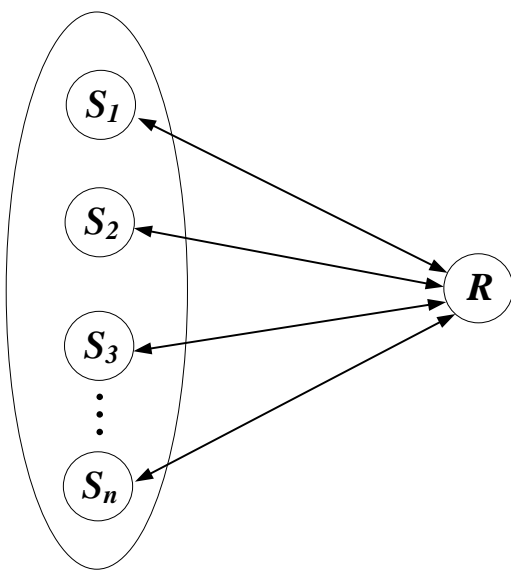

Figure 1. The supplier-to-retailer model

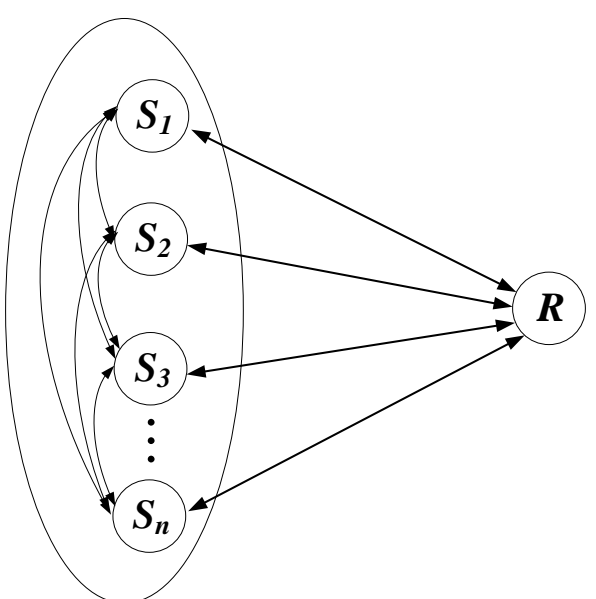

Figure 2. The supplier-to-supplier-to-retailer model 


\subsection{Case Analusis.}

Assumed that the constant $n$ is from 1 to 30, the table 1 shows the utility value of the supply chain network made up of different number of supplier nodes.

Table I The utility value of the models

\begin{tabular}{|l|l|l|l|l|l|l|l|l|}
\hline$n$ & $V_{l}$ & $V_{2}$ & $n$ & $V_{I}$ & $V_{2}$ & $n$ & $V_{l}$ & $V_{2}$ \\
\hline 1 & 2 & 2 & 11 & 22 & 132 & 21 & 42 & 462 \\
\hline 2 & 4 & 6 & 12 & 24 & 156 & 22 & 44 & 506 \\
\hline 3 & 6 & 12 & 13 & 26 & 182 & 23 & 46 & 552 \\
\hline 4 & 8 & 20 & 14 & 28 & 210 & 24 & 48 & 600 \\
\hline 5 & 10 & 30 & 15 & 30 & 240 & 25 & 50 & 650 \\
\hline 6 & 12 & 42 & 16 & 32 & 272 & 26 & 52 & 702 \\
\hline 7 & 14 & 56 & 17 & 34 & 306 & 27 & 54 & 756 \\
\hline 8 & 16 & 72 & 18 & 36 & 342 & 28 & 56 & 812 \\
\hline 9 & 18 & 90 & 19 & 38 & 380 & 29 & 58 & 870 \\
\hline 10 & 20 & 110 & 20 & 40 & 420 & 30 & 60 & 930 \\
\hline
\end{tabular}

Using the software Matlab7.0, the Figure 3 shows different utility value for the two strategies.

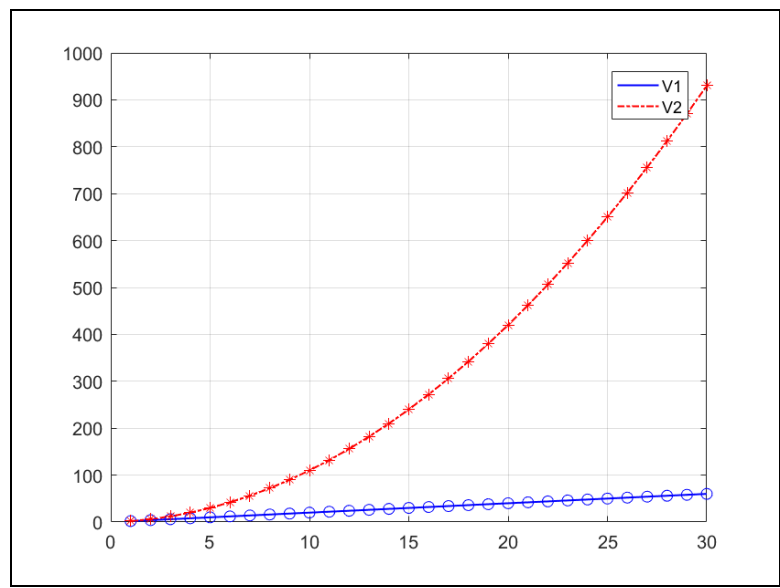

Figure 3. The graph for the utility value

As shown in the Fig.3 above, although the total utility value of the supply chain network is proportional to the number of network nodes, there is biggish difference in the growth of total utility value when take different information sharing strategies. Under the condition of the same number of supplier nodes, the total utility value of the whole supply chain network can significantly increase when there is information sharing between suppliers. That can be $V_{2}>V_{1}$. So driven by the goal of improving the overall efficiency of the entire supply chain network, it is useful to take reasonable information sharing strategies by joining as much as possible nodes not only suppliers and retailers but also distributors and customers to form supply chain network.

\section{Conclusion}

In the situation of extension of the concept of supply chain to the supply chain network based on the development of information technology especially the Internet, this paper constructed two models to calculate the utility value of the supply chain network according to the Metcalfe's law. Comparing the method of increasing the number of network nodes, it is clear that the effective way of sharing and transferring information between the nodes has more important influence on the value of a supply chain network. These two models realized a quantitative measuring the utility value of supply chain network, and provided a useful strategy for the way of sharing information among suppliers and retailers. It also provided beneficial evidence that the total utility value of the supply chain network could appear an explosive growth trend with the rising of the nodes number. 


\section{Acknowledgment}

The corresponding author is Mingjing Guo. This work was supported by the National Natural Science Foundation of China under Grant No. 41274013.

\section{References}

[1] LI Xue-long, GONG Hai-gang. Review about the big data systems, Chain Science: Information Science, 2015, 45: 1-44.

[2] YAN Xing-yu, 'Research on Modular Supply Chain Network of Retailers and Manufacturers, China Industrial Economics, 2011, 11: 139-147.

[3] David C. Hall, Can Saygin, Impact of information sharing on supply chain performance, International Journal of Advanced Manufacturing Technology, 2012, 58(1-4): 397-409.

[4] Davis L B, King R E, Hodgson T J, et al., Information sharing in capacity constrained supply chains under lost sales, International Journal of Production Research, 2011, 49(24): 7469-7491.

[5] Dejonckheere J, Disney S M, Lambrecht M R, et al., The impact of information enrichment on the bullwhip effect in supply chains: A control engineering perspective, European Journal of Operational Research, 2004, 153(3): 727-750.

[6] Lin Lifei, Dong Ming, Han Guanghua, Trust-based capacity decision under asymmetric information, Application Research of Computers, 2017, 35(3): 733-736.

[7] Inderfurth K, Sadrieh A, Voigt G, The Impact of Information Sharing on Supply Chain Performance under Asymmetric Information, Production \&Operations Management, 2013, 22,(2): 410-425.

[8] Han Guanghua, Dong Ming, Trust-embedded coordination in supply chain information sharing, International Journal of Production Research, 2015, 18: 1-16.

[9] TANG Qi, Application of Metcalfe' Law in Network Economy, Journal of Wuxi Institute of Technology, 2006, 3: 79-80. 